\title{
Hierarchical Co2P Microspheres Assembled from \\ Nanorods Grown On Reduced Graphene Oxide as Anode \\ Material for Lithium-ion Batteries
}

Chi Zhang ${ }^{a,+}$, Guanghua Jiao ${ }^{a,+}$, Fanjun Kong ${ }^{a}$, Jian Wang ${ }^{a}$, Shi Tao ${ }^{a, *}$, Lei Zhang ${ }^{a}$, Bin Qian $^{a, *}$, Yimin Chao $^{b}$

${ }^{a}$ Department of Physics and Electronic Engineering, Jiangsu Laboratory of Advanced Functional Materials, Changshu Institute of Technology, Changshu 215500, China

${ }^{b}$ School of Chemistry, University of East Anglia, Norwich, NR47TJ, UK.

+ The authors contributed equally to this work

*Corresponding author.

E-mail:taoshi@cslg.edu.cn(S.Tao);njqb@cslg.edu.cn(B.Qian).

\section{ABSTRACT}

Transition metal phosphides (TMPs) have been studied as promising electrodes for energy storage and conversion due to their large theoretical capacities and high activities. Herein, a hierarchically structured $\mathrm{Co}_{2} \mathrm{P}$ coupling with the reduced graphene oxide (RGO) composite $\left(\mathrm{Co}_{2} \mathrm{P} / \mathrm{RGO}\right)$ was synthesized by a simple solid state method for $\mathrm{Li}$ storage. The $\mathrm{Co}_{2} \mathrm{P} / \mathrm{RGO}$ hybrid composite exhibits a high reversible capacity of $610 \mathrm{mAh} \mathrm{g}^{-1}$ at $60 \mathrm{~mA} \mathrm{~g}^{-1}$, good rate capability of $327 \mathrm{mAh} \mathrm{g}^{-1}$ at $3000 \mathrm{~mA} \mathrm{~g}^{-1}$ and long cycle life (397 $\mathrm{mAh} \mathrm{g}^{-1}$ at $500 \mathrm{~mA} \mathrm{~g}^{-1}$ for after 1000 cycles). The excellent 
electrochemical performance can be attributed to the synergistic effect of $\mathrm{Co}_{2} \mathrm{P}$ micro/nano architecture and graphene modulation, which provide more activity sites for $\mathrm{Li}^{+}$-ions and maintain the structural integrity of active material. This work may provide a new path for preparation of other metal phosphides as potential electrode materials for application in energy storage fields.

Keywords: Cobalt phosphide, Graphene, Hierarchical structure, Anode, Lithium-ion batteries

\section{Introduction}

With the increasing demand for renewable and sustainable energy sources, it is critical for developing advanced energy storage devices [1]. Among various energy storage devices, lithium-ion batteries (LIBs) have been widely used in application of electrical vehicles (EVs) and energy-storage systems (EESs), due to their high energy density, long lifespan and good rate performance [2,3]. Graphite is commonly used as commercial anode material, however, its limit theoretical capacity (372 $\mathrm{mAh}^{-1}$ ) and safety issues restrict its further application [4,5]. Therefore, it is an urgent task to serach novel anode materials for next-generation LIBs. To date, various alternative anode materials have been investigated including transition metal oxides $\left(\mathrm{Fe}_{2} \mathrm{O}_{3}[6,7], \mathrm{NiO}\right.$ [8], $\mathrm{Co}_{3} \mathrm{O}_{4}$ [9], $\mathrm{SnO}_{2}$ [10,11]), sulfides $\left(\mathrm{CoS}_{2}[12,13], \mathrm{FeS}_{2}[14,15], \mathrm{SnS}_{2}[16,17], \mathrm{MoS}_{2}[18,19]\right)$ and phosphides $\left(\mathrm{NiP}_{2}[20], \mathrm{CuP}_{2}\right.$ [21], $\left.\mathrm{FeP}[22], \mathrm{Co}_{\mathbf{x}} \mathrm{P}[23,24], \mathrm{Sn}_{3} \mathrm{P}_{4}[25]\right)$ 
due to their remarkable theoretical capacities, low cost and natural abundance. Among these novel anode materials, transition metal phosphides (TMPs) demonstrate relatively low charge-discharge potentials, good thermal stabilities, and metallic features [26-28].

In particular, $\mathrm{Co}_{2} \mathrm{P}$ has received increased attention due to its specific crystal configuration, which exhibits good stability inserted by $\mathrm{Li}^{+}$-ions and exhibits high redox reacivity and high capacity for LIBs [29-32]. However, its intrinsically low electronic conductivity and large volume expansion during the charging-discharging process result in poor rate capability and cyclability. The combination of functional carbon materials (e.g., carbon tubes and graphene) has been proven an effectively way to enhance the electrochemical performance [33-35]. In addition, most of the existing methods to prepare $\mathrm{Co}_{2} \mathrm{P}$ composites use the toxic alkylphosphine, organic reagent and surfactants, which limit its practical application. Thus, a simple synthetic process for TMPs involve the use non-toxic and inexpensive raw materials is highly expected.

In this paper, we present a simple solid-state strategy to synthesize hierarchical $\mathrm{Co}_{2} \mathrm{P}$ microspheres/reduced graphene oxide (RGO) composite, which consists of interconnected nanorods grown on the RGO layers. The electrochemical results confirm that the performance of $\mathrm{Co}_{2} \mathrm{P}$ was greatly enhanced by the RGO modification. Benefitting from the RGO wrapping and the micro/nano architecture, which can release the 
volume change and maintain the structural stability, the $\mathrm{Co}_{2} \mathrm{P} / \mathrm{RGO}$ hybrid composite delivers superior lithium storage properties.

\section{Experimental section}

\subsection{Synthesis}

Graphene oxide (GO) was synthesized by a modified Hummers method as the previous report [36]. For synthesis of $\mathrm{Co}_{2} \mathrm{P} / \mathrm{RGO}, 10 \mathrm{mg} \mathrm{GO}$ was dispersed in $30 \mathrm{~mL}$ distilled water and ultrasonic treatment for $1 \mathrm{~h} \mathrm{t}$. After that, $1 \mathrm{mmol} \mathrm{Co}\left(\mathrm{CH}_{3} \mathrm{COO}\right)_{2} \cdot 4 \mathrm{H}_{2} \mathrm{O}$ were added into the above solution, then continuous stirring for another $2 \mathrm{~h}$. The solution was transfer to air dry oven to evaporate water. The obtained powder was mixed $5 \mathrm{mmol}$ $\mathrm{NaH}_{2} \mathrm{PO}_{2}$ and thoroughly ground to homogenous mixture in an agate mortar. The mixture was transferred to a porcelain boat, which was then wrapped with a piece of tinfoil paper. The half-sealed porcelain boat was put into a quartz tube, and then heated to $100{ }^{\circ} \mathrm{C}$ with a speed $5{ }^{\circ} \mathrm{C} / \mathrm{min}$ under Ar atmosphere, maintaining at $100{ }^{\circ} \mathrm{C}$ for 30 min and then heated to $350{ }^{\circ} \mathrm{C}$ for $2 \mathrm{~h}$. The obtained black powder was washed with distilled water and ethyl alcohol several times and dried in vacuum at $60{ }^{\circ} \mathrm{C}$ for $24 \mathrm{~h}$. The bare $\mathrm{Co}_{2} \mathrm{P}$ was prepared by direct mixing $\mathrm{Co}\left(\mathrm{CH}_{3} \mathrm{COO}\right)_{2} \cdot 4 \mathrm{H}_{2} \mathrm{O}$ and $\mathrm{Na}_{2} \mathrm{HPO}_{2}$ and then was calcined at the same steps without using GO. The $\mathrm{Co}_{2} \mathrm{P}-\mathrm{RGO}$ mixture sample was synthesized by the simple direct ball mixing of $\mathrm{Co}_{2} \mathrm{P}$ and $\mathrm{RGO}$ with a weight ratio of 10:1. 


\section{Materials characterization}

The phase of as-prepared samples were tested by X-ray diffractometer (Bruker APEX) $(\mathrm{Cu}-\mathrm{K}, \lambda=1.5406 \AA$ A). Scanning electron microscopy (FE-SEM, ZEISS) and transmission electron microscopy (TEM, JEOL- 2000CX) were applied to evaluated the morphology of samples. The thermogravimetric analysis (TGA, SDTA851) was used to estimate the graphene content in air. The X-ray photoelectron spectroscopy (XPS, ESCALAB 250) were employed to investigate chemical structure. Raman spectra were performed on Raman spectrometer (Horiba Xplora). The $\mathrm{N}_{2}$ adsorption/desorption measurements were tested by an ASAP2020 instrument. The XANES (X-ray Absorption Near Edge Structure) spectroscopy of C K-edge was collected in total electron yield (TEY) mode at the beamline BL12B in the national synchrotron radiation laboratory (NSRL).

\subsection{Electrochemical measurements}

The working electrodes were containing $\mathrm{Co}_{2} \mathrm{P} / \mathrm{RGO}$ (or $\mathrm{Co}_{2} \mathrm{P}$ ), acetylene black and poly (vinyl difluoride) (PVDF) (70:20:10 wt/wt/wt) with N-methyl-2-pyrrolidone (NMP) solvent to form slurry. Then it was casted on copper $(\mathrm{Cu})$ foil and dried at $100{ }^{\circ} \mathrm{C}$ for $12 \mathrm{~h}$. The cells (CR2016) were assembled in argon glove box, $1 \mathrm{M} \mathrm{LiPF}$ (ethylene carbonate/dimethyl carbonate with a 1:1 volume ratio) as the electrolyte, metallic lithium and Celgard 2400 as counter electrode and separator, 
respectively. The electrochemical tests was recorded on a battery test system (Land CT 2001A) between 0.01 and 3.0 V. Electrochemical impedance spectroscopy (EIS) and Cyclic voltammetry (CV) curves were tested on the VSP electrochemical workstation (Bio-logic, France).

\section{Results and discussion}

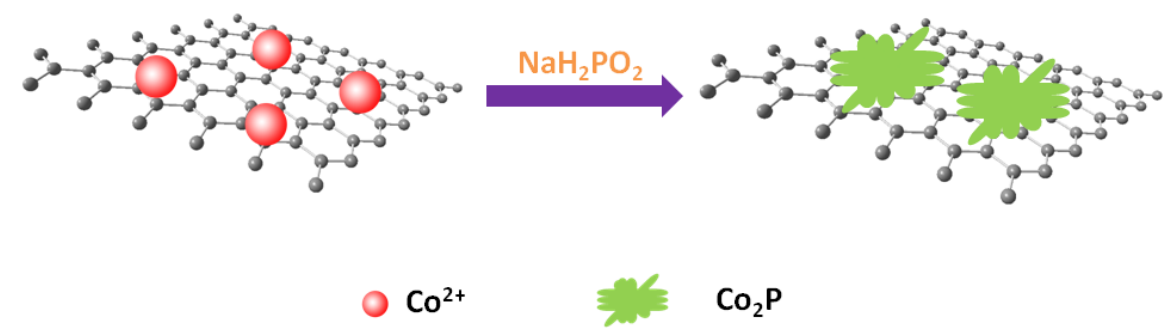

Scheme 1. Schematic illustration for the synthesis of $\mathrm{Co}_{2} \mathrm{P} / \mathrm{RGO}$ sample.

The schematic illustration for the synthesis of $\mathrm{Co}_{2} \mathrm{P} / \mathrm{RGO}$ hybrid composite is shown in Scheme 1. In briefly, the $\mathrm{Co}^{2+}$ ions were adsorbed on the surface of GO through the electrostatic force, and then mixing with $\mathrm{NaH}_{2} \mathrm{PO}_{2}$. A low temperature phosphidation procedure was introduced to convert above mixture into $\mathrm{Co}_{2} \mathrm{P} / \mathrm{RGO}$.

Fig. 1a shows the XRD patterns of as-prepared bare $\mathrm{Co}_{2} \mathrm{P}$ and $\mathrm{Co}_{2} \mathrm{P} / \mathrm{RGO}$, which is corresponding to standard orthorhomic structure of $\mathrm{Co}_{2} \mathrm{P}$ (JCPDS Card. No. 32-0306). The results are consistent with the previous reports, indicating that both bare $\mathrm{Co}_{2} \mathrm{P}$ and $\mathrm{Co}_{2} \mathrm{P} / \mathrm{RGO}$ composites are successfully synthesized without other impurities by a simple solid reaction. $[30,36]$ The characteristic peak of GO diappears, indicating that GO has been adequately 
reduced after high temperature calcination.[17] The morphologies and microstructure are shown in Fig. 1(b-f). Obviously, the $\mathrm{Co}_{2} \mathrm{P}$ micron spheres are grown on the graphene sheets. The SEM images of $\mathrm{Co}_{2} \mathrm{P}$ without graphene are shown in Figure $\mathrm{S} 1$, which present the similar morphology with $\mathrm{Co}_{2} \mathrm{P} / \mathrm{RGO}$. The TEM image of $\mathrm{Co}_{2} \mathrm{P} / \mathrm{RGO}$ reveals that flower-like spheres with an average size of $0.5-1.0 \mathrm{um}$, which are assembled by nanorods, distrbute on the graphene uniformly (Fig. 1c). The HRTEM image presents the $\mathrm{Co}_{2} \mathrm{P}$ particles are tightly grown on RGO layer (Fig. 1d). Moreover, the lattice spacing of $0.28 \mathrm{~nm}$ can be indexed to the (120) plane indicating good crystallization. EDX elemental mapping images of Co, P and C for a single $\mathrm{Co}_{2} \mathrm{P}$ nanorod on $\mathrm{RGO}$ further demonstrating that the $\mathrm{Co}_{2} \mathrm{P}$ nanoparticles encapsulated by $\mathrm{RGO}$ and elements are homogeneously distributed (Fig. 2f). 

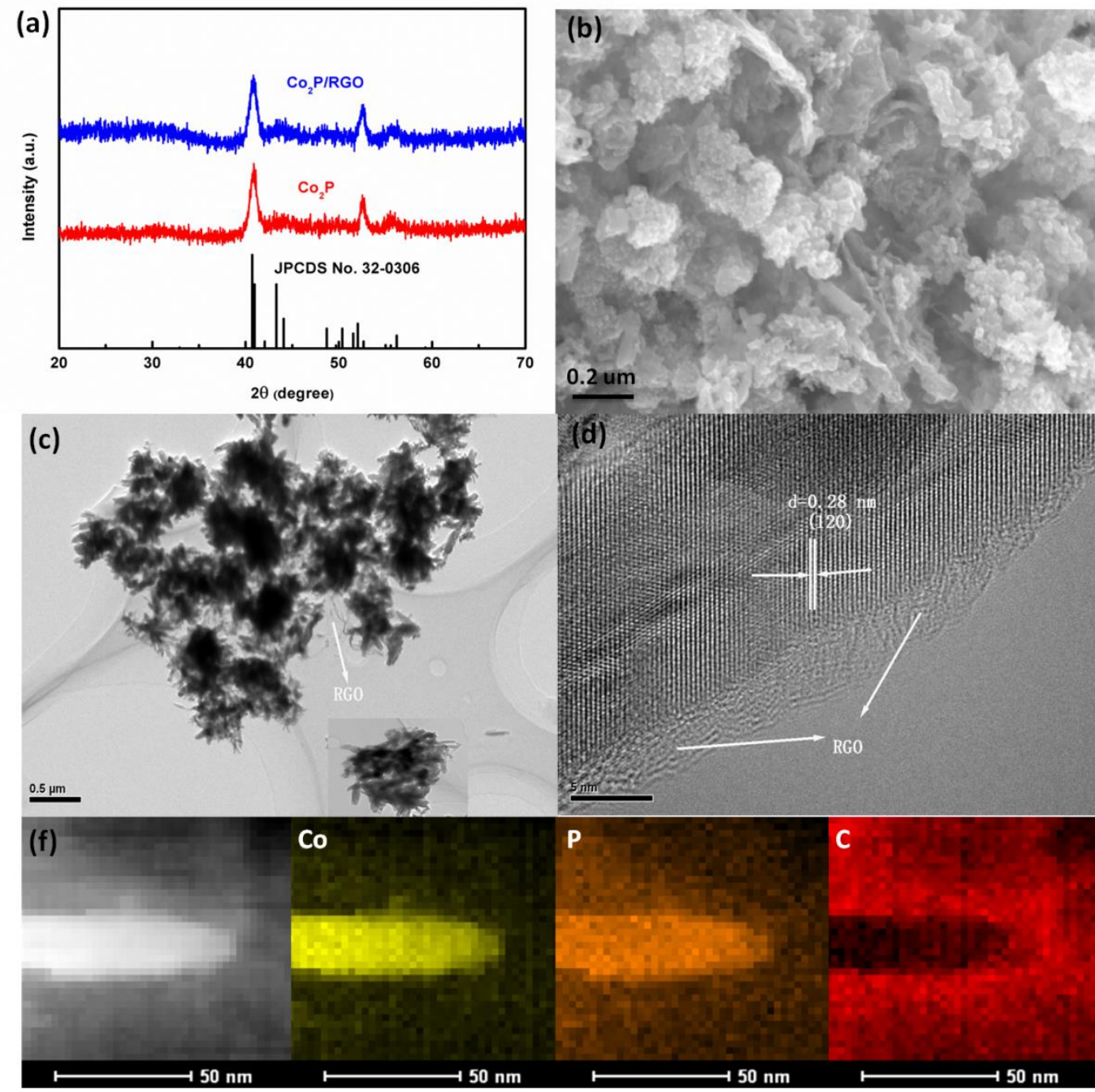

Fig. 1 (a) XRD patterns for $\mathrm{Co}_{2} \mathrm{P}$ and $\mathrm{Co}_{2} \mathrm{P} / \mathrm{RGO}$ samples. (b) SEM image for $\mathrm{Co}_{2} \mathrm{P} / \mathrm{RGO}$. (c) and (d) TEM images of $\mathrm{Co}_{2} \mathrm{P} / \mathrm{RGO}$. (f) TEM elemental mapping for $\mathrm{Co}_{2} \mathrm{P} / \mathrm{RGO}$.

Raman spectroscopy was used to confirm the existence of RGO (See Figure S2). There are two characteristic peaks located at 1349 $\mathrm{cm}^{-1}$ (D-band) and $1592 \mathrm{~cm}^{-1}$ (G-band). Compare to GO, the higher $\mathrm{I}_{\mathrm{D}} / \mathrm{I}_{\mathrm{G}}$ ratio in the $\mathrm{Co}_{2} \mathrm{P} / \mathrm{RGO}$ suggesting that the $\mathrm{Co}_{2} \mathrm{P}$ nanorods distributed on the RGO layers and induce more disorder $[37,38]$. The carbon content in the hybrid composite is determined by TGA curve (Figure S3). The weight loss from $400{ }^{\circ} \mathrm{C}$ to $600{ }^{\circ} \mathrm{C}$ is about $11.7 \%$ can be attributed to RGO. 
To further study the effect of $\mathrm{RGO}$ on $\mathrm{Co}_{2} \mathrm{P}$ electrode, the XANES (X-ray Absorption Near Edge Structure) spectroscopy of C K-edge are performed. As shown in Fig. 2a, the feature A1 and A3 can be assigned to the $\mathrm{C} 1 \mathrm{~s}$ to graphic states of $\pi^{*}$ and $\sigma^{*}$ transition, respectively [39]. The $\mathrm{A} 2$ is the $\mathrm{C}-\mathrm{O}$ or $\mathrm{C}=\mathrm{O}$ oxygenated groups induced $\mathrm{sp}^{3}$ hybridized states. The $\pi^{*}$ intensity for $\mathrm{Co}_{2} \mathrm{P} / \mathrm{RGO}$ is reduced compared with GO, which suggest more charge transfer from $\mathrm{Co}_{2} \mathrm{P}$ to graphene, indicating stronger chemical bonding between $\mathrm{Co}_{2} \mathrm{P}$ and graphene $[40,41]$. The lower intensity of feature A2 demonstrates that $\mathrm{GO}$ is almost reduced by the heating condition. Moreover, the surface area of both $\mathrm{Co}_{2} \mathrm{P}$ and $\mathrm{Co}_{2} \mathrm{P} / \mathrm{RGO}$ samples were further tested by Nitrogen adsorption/desorption isotherms (Figure S4). $\mathrm{Co}_{2} \mathrm{P}$ presents smaller specific surface area of $11.79 \mathrm{~m}^{2}$ $\mathrm{g}^{-1}$, while the specific surface area of $\mathrm{Co}_{2} \mathrm{P} / \mathrm{RGO}$ composite increases to $28.91 \mathrm{~m}^{2} \mathrm{~g}^{-1}$. The larger specific surface area could provide better electrode-electrolyte contact and more $\mathrm{Li}^{+}$-ions sites [42]. 

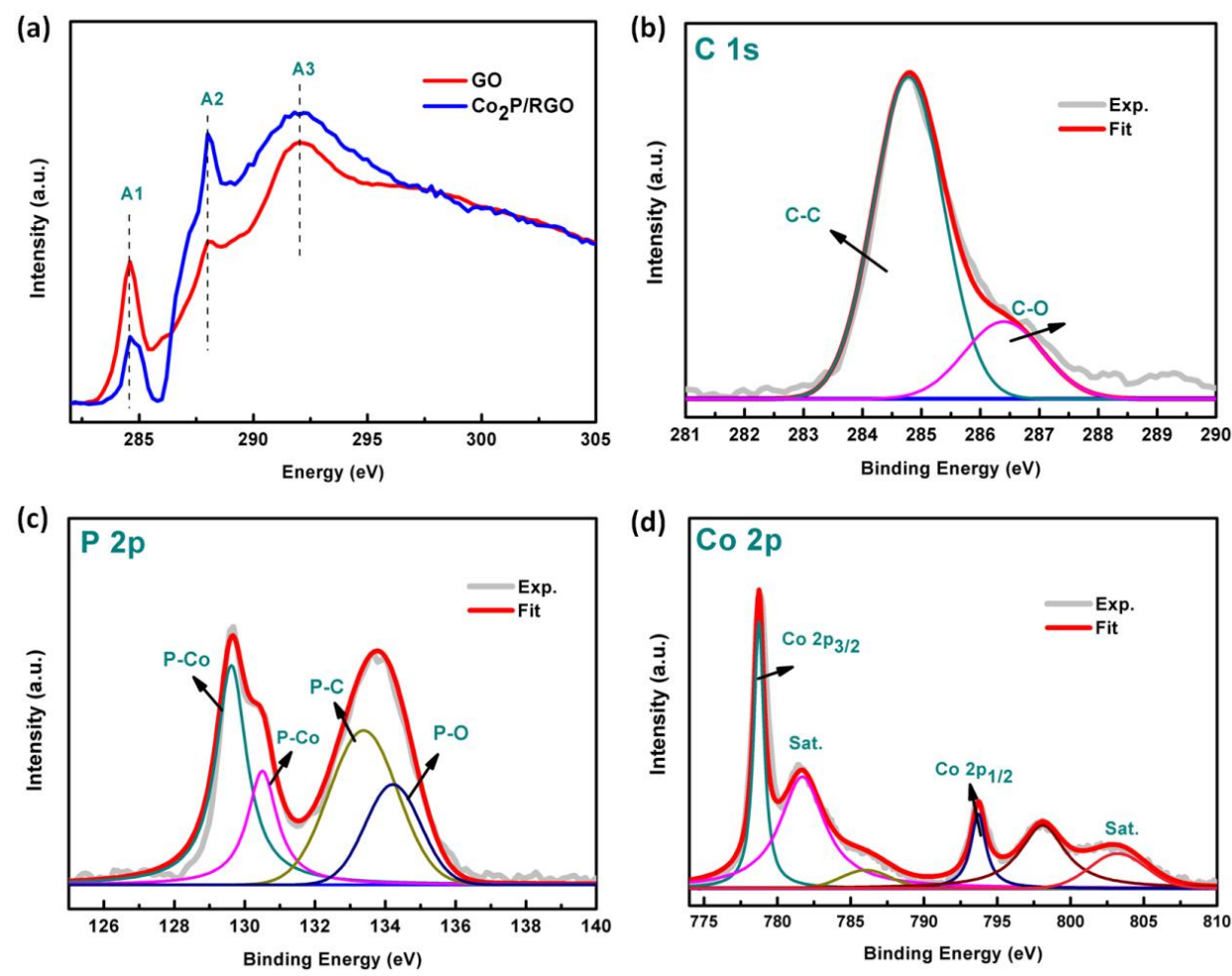

Fig. 2 (a) XANES spectrum for $\mathrm{Co}_{2} \mathrm{P} / \mathrm{RGO}$. XPS spectra of C 1s (b), P 2p (c) and $\mathrm{Co} 2 \mathrm{p}(\mathrm{d})$ for $\mathrm{Co}_{2} \mathrm{P} / \mathrm{RGO}$.

The chemical state and composition of $\mathrm{Co}_{2} \mathrm{P} / \mathrm{RGO}$ are measured by XPS. The survey XPS spectrum (Figure S5) demonstrates the existence of Co, P, C and O. The C 1s peak (Fig. 2b) at $284.6 \mathrm{eV}$ and $286.5 \mathrm{eV}$ are corresponding to $\mathrm{C}-\mathrm{C}$ and $\mathrm{C}-\mathrm{O}$ species in graphene [43]. It can be seen that the intensities of $\mathrm{C}-\mathrm{O}$ is much smaller than $\mathrm{C}-\mathrm{C}$. This result suggests that GO has been reduced that consistent with the XANES analysis. In the P 2p spectrum (Fig. 2c), two characteristic peak at $129.6 \mathrm{eV}$ and $130.5 \mathrm{eV}$ could be assigned to the $\mathrm{P} 2 \mathrm{p}_{3 / 2}$ and $\mathrm{P} 2 \mathrm{p}_{1 / 2}$ respectively. The Co $2 \mathrm{p}$ spectrum has two main peaks located at $778.2 \mathrm{eV}$ (Co $\left.2 \mathrm{p}_{3 / 2}\right)$ and $794.1 \mathrm{eV}\left(\mathrm{Co} 2 \mathrm{p}_{1 / 2}\right)$ with their respective satellite peaks (Fig. 2d). The $\mathrm{P} 2 \mathrm{p}_{3 / 2}$ peak at $129.6 \mathrm{eV}$ and the Co $2 \mathrm{p}_{3 / 2}$ peak at 781.2 $\mathrm{eV}$ can be ascribed to the binding energies for $\mathrm{P} 2 \mathrm{p}$ and Co $2 \mathrm{p}$ in 
$\mathrm{Co}_{2} \mathrm{P}[44,45]$.
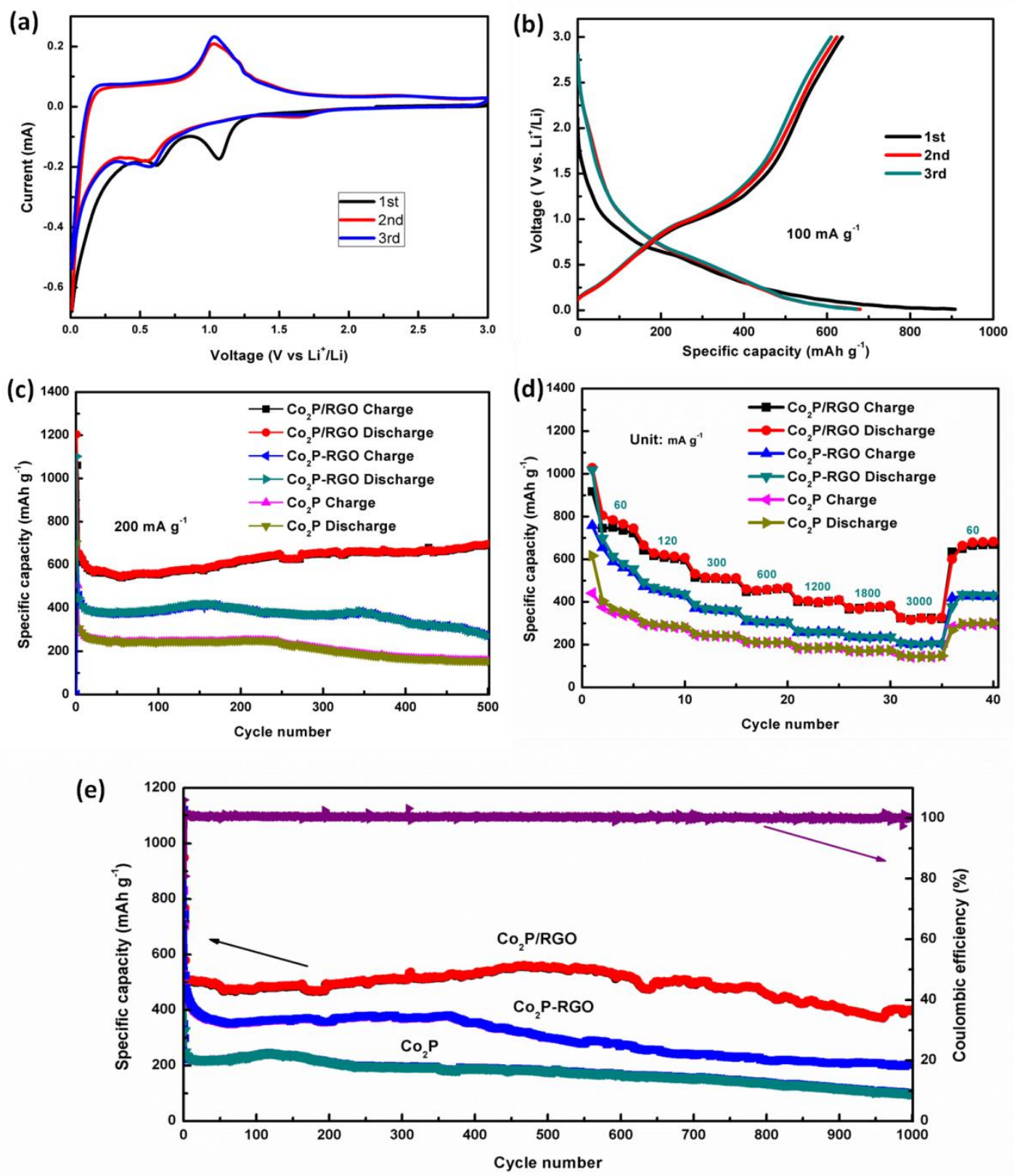

Fig. 3 (a) $\mathrm{CV}$ curves of the $\mathrm{Co}_{2} \mathrm{P} / \mathrm{RGO}$ composite at $0.2 \mathrm{mV} \mathrm{s}^{-1}$. (b)

Charge-discharge curves of $\mathrm{Co}_{2} \mathrm{P} / \mathrm{RGO}$ at $100 \mathrm{~mA} \mathrm{~g}^{-1}$. (c) Cycling performance of $\mathrm{Co}_{2} \mathrm{P} / \mathrm{RGO}$ and $\mathrm{Co}_{2} \mathrm{P}$ at $200 \mathrm{~mA} \mathrm{~g}^{-1}$. (d) Rate performance of $\mathrm{Co}_{2} \mathrm{P}$ and $\mathrm{Co}_{2} \mathrm{P} / \mathrm{RGO}$ at various current densities. (e) Cycling performance and coulombic efficiency of $\mathrm{Co}_{2} \mathrm{P}$ and $\mathrm{Co}_{2} \mathrm{P} / \mathrm{RGO}$ at $500 \mathrm{~mA} \mathrm{~g}^{-1}$.

The lithium storage performance of $\mathrm{Co}_{2} \mathrm{P} / \mathrm{RGO}$ and $\mathrm{Co}_{2} \mathrm{P}$ composites are carried out as anode materials for LIBs. The CV curves of the $\mathrm{Co}_{2} \mathrm{P} / \mathrm{RGO}$ electrode is shown in Fig. 3a. The peak at around $1.10 \mathrm{~V}$ appeared in the first discharge process, which 
corresponds to the reaction of $\mathrm{Co}_{2} \mathrm{P}+3 \mathrm{Li}^{+}+3 \mathrm{e}^{-} \rightarrow \mathrm{Li}_{3} \mathrm{P}+2 \mathrm{Co}$ [27]. Another reduction peak at about $0.60 \mathrm{~V}$ was attributed to the formation of solid electrolyte interface (SEI) film [33]. The oxidation peak at about $1.0 \mathrm{~V}$ can be owning to the decomposition of SEI and $\mathrm{Li}_{3} \mathrm{P}$ during charging. After the first cycle, $\mathrm{CV}$ curves are nearly over-lapped, suggesting the excellent cyclability. Fig. $3 b$ shows the galvanostatic charge/discharge profiles for the $\mathrm{Co}_{2} \mathrm{P} / \mathrm{RGO}$ composite at current density of $100 \mathrm{~mA} \mathrm{~g}^{-1}$. The $\mathrm{Co}_{2} \mathrm{P} / \mathrm{RGO}$ exhibits discharge and charge capacities are 908 and $637 \mathrm{mAh} \mathrm{g}^{-1}$, respectively, giving a coulmobic efficiency of $70.2 \%$, which is higher than the previous reports $[23,24]$. The good overlapping voltage curves indicate the superior reversibility during cycling. The cycling capability of bare $\mathrm{Co}_{2} \mathrm{P}, \mathrm{Co}_{2} \mathrm{P}-\mathrm{RGO}$ and $\mathrm{Co}_{2} \mathrm{P} / \mathrm{RGO}$ were measured at $200 \mathrm{~mA} \mathrm{~g}^{-1}$. As shown in Fig.3c, it can be clearly observed that $\mathrm{Co}_{2} \mathrm{P} / \mathrm{RGO}$ obtained a much higher capacity than the $\mathrm{Co}_{2} \mathrm{P}-\mathrm{RGO}$ mixture and bare $\mathrm{Co}_{2} \mathrm{P}$. In particularly, a specific capacity of $698 \mathrm{mAh} \mathrm{g}^{-1}$ was maintained for $\mathrm{Co}_{2} \mathrm{P} / \mathrm{RGO}$ after 500 cycles, while the $\mathrm{Co}_{2} \mathrm{P}-\mathrm{RGO}$ mixture begins to drop after 200 cycles (300 $\mathrm{mAh} \mathrm{g}^{-1}$ ) and bare $\mathrm{Co}_{2} \mathrm{P}$ rapidly decayed to $156 \mathrm{mAh} \mathrm{g}^{-1}$ at the same condition. Fig. $3 \mathrm{~d}$ shows the rate capability of bare $\mathrm{Co}_{2} \mathrm{P}$, $\mathrm{Co}_{2} \mathrm{P}-\mathrm{RGO}$ and $\mathrm{Co}_{2} \mathrm{P} / \mathrm{RGO}$. Specially, $\mathrm{Co}_{2} \mathrm{P} / \mathrm{RGO}$ electrode exhibits higher reversible capacities than that of bare $\mathrm{Co}_{2} \mathrm{P}$ and $\mathrm{Co}_{2} \mathrm{P}-\mathrm{RGO}$. 
The $\mathrm{Co}_{2} \mathrm{P} / \mathrm{RGO}$ electrode can still exhibit a discharge capacity of around $327 \mathrm{mAh} \mathrm{g}^{-1}$ at a current density of $3000 \mathrm{~mA} \mathrm{~g}^{-1}$. Fig. 3e presents the long cyclability at a current density of $500 \mathrm{~mA} \mathrm{~g}^{-1}$. The $\mathrm{Co}_{2} \mathrm{P} / \mathrm{RGO}$ hybrid composite dilivers excellent cyclability, a discharge capacity of about $397 \mathrm{mAh} \mathrm{g}^{-1}$ can be maintained even after 1000 cycles with a capacity retention of $77.7 \%$. In addition, the coulombic efficiency is about $100 \%$. However, the capacity retention of bare $\mathrm{Co}_{2} \mathrm{P}$ and $\mathrm{Co}_{2} \mathrm{P}-\mathrm{RGO}$ are $57.8 \%$ and $43.3 \%$ after 1000 cycles, respectively. The brilliant rate performance and cycle stability of $\mathrm{Co}_{2} \mathrm{P} / \mathrm{RGO}$ can be attributed to $\mathrm{RGO}$ encapsulation, which can not only faciliate $\mathrm{Li}^{+}$-ions transport and rapid electrons transfer in the composite, but also enhances the structure stability of $\mathrm{Co}_{2} \mathrm{P}$.
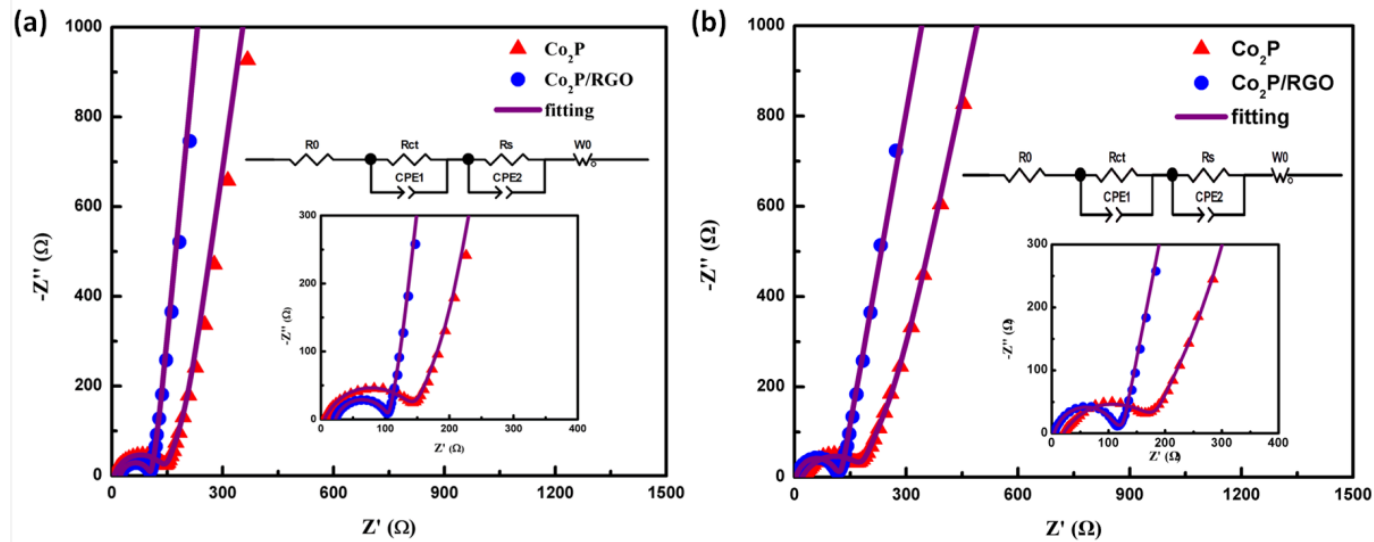

Fig. 4 Nyquist plots of $\mathrm{Co}_{2} \mathrm{P}$ and $\mathrm{Co}_{2} \mathrm{P} / \mathrm{RGO}$ (a) pristine, (b) after 50 cycles.

The Nyquist plots of the $\mathrm{Co}_{2} \mathrm{P} / \mathrm{RGO}$ and $\mathrm{Co}_{2} \mathrm{P}$ samples before and after 50 cycles are shown in Fig. 4, there are semicircles in high frequency and straight lines in the low frequency region. The diameter of 
semi-circle and the straight line correspond to the charge transfer resistance $\left(\mathrm{R}_{\mathrm{ct}}\right)$ and the $\mathrm{Li}^{+}$-ions diffusion, respectively [46-50]. The fitting results are summarized in Table $\mathrm{S} 1$. Before cycling, the $\mathrm{Co}_{2} \mathrm{P} / \mathrm{RGO}$ exhibited an $\mathrm{R}_{\mathrm{ct}}$ of $82.1 \Omega$, which is lower than that of $\mathrm{Co}_{2} \mathrm{P}(136.7 \Omega)$, indicating that the $\mathrm{Co}_{2} \mathrm{P} / \mathrm{RGO}$ has lower charge transfer resistance. Moreover, $\mathrm{Co}_{2} \mathrm{P} / \mathrm{RGO}$ delivers a higher slope, indicating the faster $\mathrm{Li}^{+}$-ions diffusion. After cycling, the change of $\mathrm{R}_{\mathrm{ct}}$ of $\mathrm{Co}_{2} \mathrm{P} / \mathrm{RGO}$ is almost negligible. While, $\mathrm{R}_{\mathrm{ct}}$ of $\mathrm{Co}_{2} \mathrm{P}$ becomes larger $(163.2 \Omega)$ and the change of impedance plot for $\mathrm{Co}_{2} \mathrm{P} / \mathrm{RGO}$ electrode is much smaller than $\mathrm{Co}_{2} \mathrm{P}$. Hence, the enhancement of the electrochemical properties could be ascribed to the realization of micro/nano structure of $\mathrm{Co}_{2} \mathrm{P}$ particles by incorporation of into the graphene network that could eventually lead to fast electrons and $\mathrm{Li}^{+}$-ions transport.
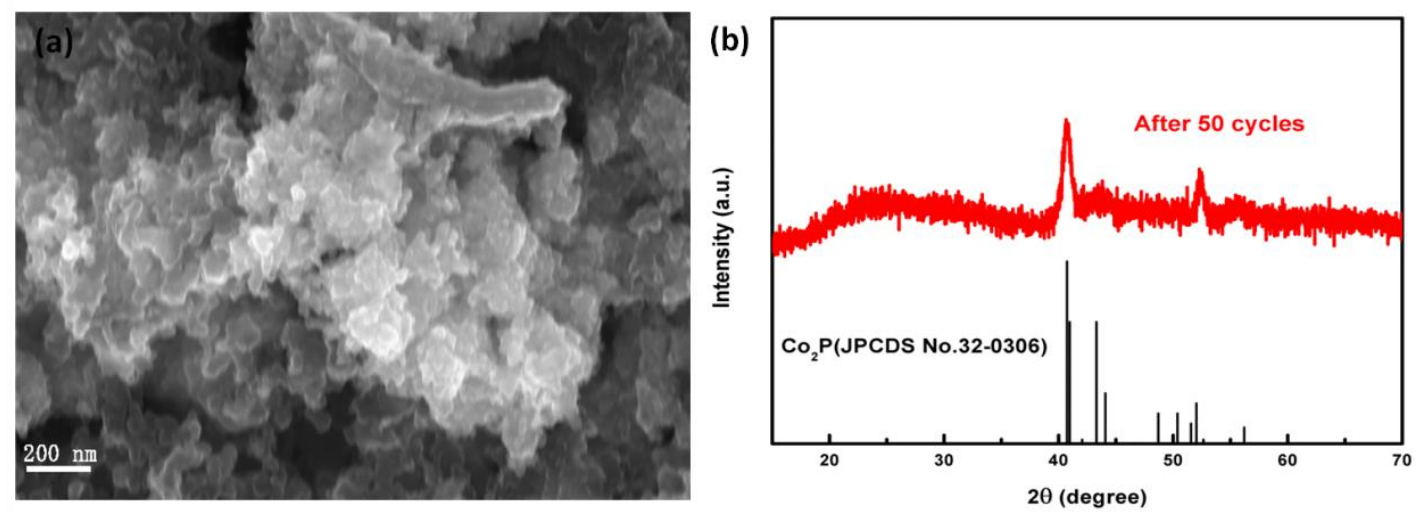

Fig. $5 \mathrm{Co}_{2} \mathrm{P} / \mathrm{RGO}$ sample after charging/discharging 50 cycles (a) Ex-situ SEM image, (b) Ex-situ XRD pattern.

To further understand the superior lithium storage performance of the $\mathrm{Co}_{2} \mathrm{P} / \mathrm{RGO}$ composite, the $\mathrm{P} 2 \mathrm{p}$ XPS spectroscopy after 50 charge/discharge cycles were collected in the Figure. S6. It can be seen 
that the P-C bond still exists, indicating that the hybrid structure are well maintained during the cycling. Ex-situ SEM and XRD tests were employed after charge/discharge 50 cycles at current density of $200 \mathrm{~mA}$ $\mathrm{g}^{-1}$. As shown in Fig. 5, the SEM image shows that morphology and microstructure of hybrid composite was well maintained. Moreover, the XRD pattern is still match with the phase $\mathrm{Co}_{2} \mathrm{P}$. These results further indicate the excellent cyclic capability of the $\mathrm{Co}_{2} \mathrm{P} / \mathrm{RGO}$ composite.

\section{Conclusions}

In summary, we developed a facile method to synthesize hierarchically structured $\mathrm{Co}_{2} \mathrm{P} / \mathrm{RGO}$ hybrid composite and use as anode material for lithium-ion batteries. The $\mathrm{Co}_{2} \mathrm{P} / \mathrm{RGO}$ hybrid composite exhibited an impressive cyclability of $399 \mathrm{mAh} \mathrm{g}^{-1}$ at 500 $\mathrm{mA} \mathrm{g}^{-1}$ after 1000 cycles and retained a discharge capacity of 327 $\mathrm{mAh} \mathrm{g}^{-1}$ even at a high current density of $3000 \mathrm{mAh} \mathrm{g}^{-1}$. The unique architecture and graphene modification are responsible for the outstanding electrochemical performance. Such inexpensive synthetic approach and intriguing electrochemical properties of $\mathrm{Co}_{2} \mathrm{P} / \mathrm{RGO}$ make it as a potential anode material for advanced LIBs.

\section{Acknowledgements}

This work is partly supported by the National Natural Science Fo undation of China (No. 11705015, 11605002 and 61604021), Scienc 
e and Technology Plan Project of Suzhou (No. SYG201738), and N atural Science Foundation of Jiangsu Educational Department (No. 15KJ A430001), Six-talent Peak of Jiangsu Province (No. 2012-XCL-036). We sincerely acknowledge the staff of the beamline BL12B in the nati onal synchrotron radiation laboratory (NSRL).

\section{References}

[1] S. Chu, A. Majumdar, Opportunities and challenges for a sustainable energy future, Nature 488 (2012) 294-303.

[2] M. Armand, J. M. Tarascon, Building better batteries, Nature 451 (2008) $652-657$.

[3] B. Dunn , H. Kamath, J. M. Tarascon, Electrical energy storage for the grid: A battery of choices, Science 334 (2011) 928-935.

[4] G. Chen, L. T. Yan, H. M. Luo, S. J. Guo, Nanoscale engineering of heterstructured anode materials for boosting lithium-ion storage, Adv. Mater. 28 (2017) 7580-7602.

[5] L. W. Ji, Z. Lin, M. Alcoutlabi, X. W. Zhang, Recent developments in nanostructured anode materials for rechargeable lithium-ion batteries, Energy Environ. Sci. 4 (2011) 2682-2699.

[6] Z. Y. Wang, D. Y. Luan, S. Madhavi, C. M. Li, X. W. Lou, $\alpha-\mathrm{Fe}_{2} \mathrm{O}_{3}$ nanotubes with superior lithium storage capability, Chem. Commun. 47 (2011) 8061-8063.

[7] T. C. Jiang, F. X. Bu, X. X. Feng, I. Shakir, G. L. Hao, Y. X. Xu, Porous $\mathrm{Fe}_{2} \mathrm{O}_{3}$ nanoframeworks encapsulated within three-demensional graphene as 
high-performance flexible anode for lithium-ion battery, ACS nano 5 (2017) $5140-5147$

[8] C. Z. Wang, Y. J. Zhao, D. Z. Su, C. H. Ding, L. Wang, D. Yan, J. B. Li, H. B. Jin, Synthesis of $\mathrm{NiO}$ nano octahedron aggregates as high-performance anode materials for lithium ion batteries, Electrochim. Acta 231 (2017) 272-278.

[9] H. R. Du, C. Yuan, K. F. Huang, W. H. Wang, K. Zhang, B. Y. Geng, A novel gelatin-guided mesoporous bowknot-like $\mathrm{Co}_{3} \mathrm{O}_{4}$ anode material for high-performance lithium-ion batteries, J. Mater. Chem. A 11 (2017) 5342-5350.

[10] W. J. Dong, J. J. Xu, C. Wang, Y. Lu, X. Y. Liu, X. Wang, X. T. Yuan, Z. Wang, T. Q. Lin, M. L. Sui, I. W. Chen, F. Q. Huang, A robust and conductive black Tin oxide nanostructure makes efficient lithium-ion batteries possible, Adv. Mater. DOI: 10.1002/adma.201700136.

[11] X. S. Zhou, L. J. Wan, Y. G. Guo, Binding $\mathrm{SnO}_{2}$ nanocrystals in nitrogen-doped graphene sheets as anode materials for lithium-ion batteries, Adv. Mater. 25 (2013) 2152-2157.

[12] Q. F. Wang, R. Q. Zou, W. Xia, J. Ma, B. Qiu, A. Mahmood, R. Zhao, Y. Yang, D. G. Xia, Q. Xu, Facile synthesis of ultrasmall $\mathrm{CoS}_{2}$ nanoparticles within thin $\mathrm{N}$-doped porous carbon shell for high performance lithium-ion batteries, Small 11 (2015) 2511-2517.

[13] G. C. Huang, T. Chen, Z. Wang, K. Chang, W. X. Chen, Synthesis and electrochemical performances of cobalt sulfides/graphene nanocomposite as anode material of Li-ion battery, J. Power Sources 235 (2013) 122-128. 
[14] J. R. He, Q. Li, Y. F. Chen, C. Xu, K. R. Zhou, X. Q. Wang, W. L. Zhang, Y. R. $\mathrm{Li}$, Self-assembled cauliflower-like $\mathrm{FeS}_{2}$ anchored in graphene foam as free-standing anode for high-performance lithium-ion batteries, Carbon 114 (2017) 111-116.

[15] G. X. Pan, F. Cao, X. H. Xia, Y. J. Zhang, Exploring hierarchical $\mathrm{FeS}_{2} / \mathrm{C}$ composite nanotubes arrays as advanced cathode for lithium ion batteries, J. Power Sources 332 (2016) 383-388.

[16] B. H. Qu, C. Z. Ma, G. Ji, C. H. Xu, J. Xu, Y. S. Meng, T. H. Wang, J. Y. Lee, Layered $\mathrm{SnS}_{2}$-reduced graphene oxide composite-a high-capacity, high-rate, and long-cycle life sodium-ion battery anode material, Adv. Mater. 26 (2014) 3854-3859.

[17] Y. Jiang, Y. Z. Feng, B. J. Xi, S. S. Kai, K. Mi, J. K. Feng, J. H. Zhang, S. L. Xiong, Ultrasmall $\mathrm{SnS}_{2}$ nanoparticles anchored on well-distribued nitrogen-doped graphene sheets for Li-ion and Na-ion batteries, J. Mater. Chem. A 27 (2016) 10719-10726.

[18] T. Xiang, Q. Fang, H. Xie, C. Q. Wu, C. D. Wang, Y. Zhou, D. B. Liu, S. M. Chen, A. Khalil, S. Tao, Q. Liu, L. Song, Vertical 1T-MoS 2 nanosheets with expanded interlayer spacing edged on a graphene frame for high rate lithium-ion batteries, Nanoscale 9 (2017) 6975-6983.

[19] Z. M. Wang, G. Wei, L. Ozawa, Y. L. Cai, Z. X. Cheng, H. Kimura, Nanoporous $\mathrm{MoS}_{2} / \mathrm{C}$ composite for high performance lithium ion battery anode material, Electrochim. Acta 239 (2017) 74-83. 
[20] P. L. Lou, Z. H. Cui, Z. Q. Jia, J. Y. Sun, Y. B. Tan, X. X. Guo, Monodispersed carbon-coated cubic $\mathrm{NiP}_{2}$ nanoparticles anchored on carbon nanotubes as ultra-long-life anodes for reversible lithium storage, ACS Nano 11 (2017) $3705-3715$.

[21] S. O. Kim, A. Manthiram, Phosphorus-rich $\mathrm{CuP}_{2}$ embedded in carbon matrix as a high-performance anode for lithium-ion batteries, ACS Appl. Mater. Interfaces 9 (2017) 16221-16227.

[22] F. Han, C. Z. Zhang, J. X. Yang, G. Z. Ma, K. J. He, X. K. Li, Well-dispersed and porous FeP@C nanoplates with stable and ultrafast lithium storage performance through conversion reaction mechamism, J. Mater. Chem. A 4 (2016) 12781-12789.

[23] J. Yang, Y. Zhang, C. C. Sun, H. Z. Liu, L. Q. Li, W. L. Si, W. Huang, Q. Y. Yan, X. C. Dong, Graphene and cobalt phosphide nanowire composite as an anode material for high performance lithium-ion batteries, Nano Res. 9 (2016) $612-621$

[24] Q. S. Xie, D. Q. Zeng, P. Y. Gong, J. Huang, Y. T. Ma, L. S. Wang, D. L. Peng, One-pot fabrication of graphene sheets decorated $\mathrm{Co}_{2} \mathrm{P}-\mathrm{Co}$ hollow nanospheres for advanced lithium ion battery anodes, Electrochim. Acta 232 (2017) 465-473.

[25] S. L. Liu, H. Z. Zhang, L. Q. Xu, L. B. Ma, X. X. Chen, Solvothermal preparation of tin phosphide as a long-life anode for advanced lithium and sodium ion batteries, J. Power Sources 304 (2016) 346-353. 
[26] M. Walter, M. I. Bodnarchuk, K. V. Kravchyk, M. V. Kovalenko, Evalution of metal phosphide nanocrystals as anode materials for Na-ion batteries, Chimia 69 (2015) 724-728.

[27] M. Sun, H. J. Liu, J. H. Qu, J. H. Li, Earth-rich transition metal phosphide for energy conversion and storage, Adv. Energy Mater. 6 (2016) 1600087.

[28] X. He, R. Wang, M. C. Stan, E. Paillard, J. Wang, H. Frielinghaus, J. Li, In situ investigations on the structural and morphological changes of metal phosphides as anode materials in lithium-ion batteries, Adv. Mater. Interfaces 4 (2017) 1601047.

[29] M. H. Chen, W. W Zhou, M. L. Qi, J. H. Yin, X. H. Xia, Q. G. Chen, Exploring highly porous $\mathrm{Co}_{2} \mathrm{P}$ nanowire arrays for electrochemical energy storage, J. Power Sources, 342 (2017) 964-969.

[30] X. j. Chen, M. Cheng, D. Chen, R. M. Wang, Shape-controlled synthesis of $\mathrm{Co}_{2} \mathrm{P}$ nanostructures and their application in supercapacitors, ACS Appl. Mater. Interfaces 8 (2016) 3892-3900.

[31]S. L. Liu, L. Yan, H. L. Li, Solvothermal synthesis of flower-like $\mathrm{Co}_{2} \mathrm{P}$ nanostructures and its electrochemical performance, Sci. Adv. Mater. 6 (2014) $746-750$

[32] D. Yang, J. X. Zhu, X. H. Rui, H. T. Tan, R. Cai, H. E. Hoster, D. T. W. Yu, H. H. Hng, Q. Y. Yan, Synthesis of cobalt phosphides and their application as anodes for lithium ion batteries, ACS Appl. Mater. Interfaces 5( 2013) 1093-1099. 
[33] A. L. Lu, X. Q. Zhang, Y. Z. Chen, Q. S. Xie, Q. Q. Qi, Y. T. Ma, D. L. Peng, Synthesis of $\mathrm{Co}_{2} \mathrm{P} /$ graphene nanocompsoites and their enhanced properties as anode materials for lithium ion batteries, J. Power Sources 295 (2015) 329-335.

[34] Y. Zhao, L. P. Wang, M. T. Sougrati, Z. X. Feng, Y. Leconte, A. Fisher, ,. Srinivasan, Z. Xu, A review on design strategies for carbon based metal oxides and sulfides nanocomposites for high performance Li and $\mathrm{Na}$ battery anodes, Adv. Energy Mater. 7 (2017) 1601424.

[35] C. Wu, Y.J. Yang, D. Dong, Y. H. Zhang, J. H. Li, In situ coupling of CoP polyhedrons and carbon nanotubes as highly efficient hydrogen evolution reaction electrocatalyst, Small, 13 (2017) 1602873.

[36] M. Cheng, H. Fan, Y. Xu, R. Wang, X. Zhang, Hollow $\mathrm{Co}_{2} \mathrm{P}$ nanoflowers assembled from nanorods for ultralong cycle-life supercapacitors, Nanoscale, 9 (2017) 14162-14171.

[37]D. C. Marcano, D. V. Kosynkin, J. M. Berlin, A. Sinitskii, Z. Sun, A. Slesarev, L. B. Alemany, W. Lu, J. M. Tour, Improved synthesis of graphene oxide, ACS nano 2010, 4 4806-4814.

[38] S. Tao, W. F. Huang, G. X. Wu, X. B. Zhu, X. B. Wang, M. Zhang, S. H. Wang, W. S. Chu, L. Song, Z. Y. Wu. Performance enhancement of lithium-ion battery with LiFePO ${ }_{4} @$ C/RGO hybrid electrode. Electrochimi. Acta 2014; 144: 406-411.

[39] S. J. Patil, J. H. Kim, D. W. Lee, Graphene-nanosheet wrapped cobalt sulphide as a binder free hybrid electrode for asymmetric solid-state supercapacitor, 342 (2017) 652-665. 
[40] J. Zhong, J. J. Deng, B. H. Mao, T. Xie, X. H. Sun, Z. G. Mou, C. H. Hong, P. Yang, S. D. Wang. Probing solid state N-Doping in graphene by X-ray absorption near-edge structure spectroscopy. Carbon 2012; 50: 321-41.

[41] R. P. Gandhiraman, D. Nordlind, C. Jassica, J. E. Koehne, B. Chen, M. Meyyappan. X-ray absorption study of graphene oxide and transition metal oxide nanocomposites. J. Phys. Chem. C 2014; 118: 18706-12.

[42] C. H. Chuang, T. F. Wang, Y. C. Shao, Y. C. Yeh, D. Y. Wang, C. W. Chen, J. W. Chiou, S. C. Ray, W. F. Pong, L. Zhang, J. F. Zhu. The effect of thermal reduction on the photoluminescence and electronic structure of graphene oxides. Sci. Rep. 2014; 4: 4525.

[43] X. M. Zhu, X. Y. Jiang, X. Chen, X. L. Liu, L. F. Xiao, Y. L. Cao, $\mathrm{Fe}_{2} \mathrm{O}_{3}$ amorphous nanoparticles/graphene composite as high-performance anode materials for lithium-ion batteries, J. Alloys and Compd. 711 (2017) 15-21.

[44] D. Das, A. Das, M. Reghunath, K. K. Nanda, Phosphine-free avenue to $\mathrm{Co}_{2} \mathrm{P}$ nanoparticle encapsulated N, P Co-doped CNTs: a novel non-enzymatic glucose sensor and an efficient electrocatalyst for oxygen evolution reaction, Green Chem. 19 (2017) 1327-1335.

[45] Z. Y. Jin, P. P. Li, D. Xiao, Metallic $\mathrm{Co}_{2} \mathrm{P}$ ultrathin nanowires distinguished from $\mathrm{CoP}$ as robust electrocatalysts for overall water-splitting, Green Chem. 18 (2016) 1459-1464.

[46] M. H. Zhuang, X. W. Ou, Y. B. Dou, L. L. Zhang, Q. C. Zhang, R. Z. Wu, Y. Ding, M. H. Shao, Z. T. Luo, Polymer-embedded fabrication of $\mathrm{Co}_{2} \mathrm{P}$ 
nanoparticles encapsulated in N, P-doped graphene for hydrogen generation, Nano Lett. 16 (2016) 4691-4698.

[47] J. M. Wang, W. R. Yang, J. Q. Liu, $\mathrm{CoP}_{2}$ nanoparticles on reduced graphene oxide sheets as super-efficient bifunctional electrocatalyst for full water splitting, J. Mater. Chem. A 4 (2016) 4686-4690.

[48] Y. Y. Feng, H. J. Zhang, Y. P. Mu, W. X. Li, J. L. Sun, K. Wu, Y. Wang, Monodisperse sandwich-like coupled quasi-graphene sheets encapsulating $\mathrm{Ni}_{2} \mathrm{P}$ nanoparticles for enhanced lithium-ion batteries, Chem. Eur. J. 21 (2015) 9229-9235.

[49] X. Y. Zhou, S. M. Chen, J. Yang, T. Bai, Y. P. Ren, H. Y. Tian, Metal-organic frameworks derived okra-like $\mathrm{SnO}_{2}$ encapsulated in nitrogen-doped graphene for lithium ion battery, ACS Appl. Mater. Interfaces 9 (2017) 14309-14318.

[50] J. Xie, S. Y. Liu, G. S. Cao, T. J. Zhu, X. B. Zhao, Self-assemblely of $\mathrm{CoS}_{2}$ /graphene nanoarchitecture by a facile one-pot route and its improved electrochemical Li-Storage properties, Nano Energy 2 (2013) 49-56. 